\title{
ANALISIS SUPPLY AND DEMAND TENAGA KERJA BIDANG BANGUNAN KABUPATEN KARANGANYAR
}

\author{
Fajar Avani', A G Tamrin², Taufiq Lilo Adi Sucipto \\ Email :jajang995@gmail.com
}

\begin{abstract}
Abstrak
Tujuan penelitian ini adalah : (1) Mengetahui kondisi ketersediaan tenaga kerja bidang bangunan di Kabupaten Karanganyar, (2) Mengetahui kondisi kebutuhan tenaga kerja bidang bangunan di Kabupaten Karanganyar, (3) Mengetahui kesesuaian kualifikasi dan kompetensi antara ketersediaan dan kebutuhan tenaga kerja bidang bangunan di Kabupaten Karanganyar. Penelitian ini merupakan penelitian kualitatif dengan pendekatan studi kasus. Pengumpulan data dengan dokumen dan wawancara, analisis data menggunakan model analisis data interaktif dengan melalui 3 tahap, (1) reduksi data, (2) penyajian data, (3) kesimpulan/ verifikasi. Data diperoleh dari Dinas Tenaga Kerja dan Asosiasi Kontraktor di Karanganyar. Hasil penelitian menunjukkan bahwa (1) ketersediaan tenaga kerja bidang bangunan kabupaten Karanganyar pada tahun 2018 dari SMK dan Dinas Tenaga Kerja sebanyak 111 orang, keterampilan yang tersedia adalah pertukangan dan Teknik Gambar Bangunan. (2) Kebutuhan tenaga kerja bidang bangunan kabupaten Karanganyar pada tahun 2018 untuk satu proyek sebanyak 106 orang. Kompetensi kerja yang dibutuhkan adalah tenaga ahli, tenaga terampil, dan tenaga kasar. (3) Kesesuaian antara skill dengan bidang pekerjaan bangunan sudah sesuai, namun ada ketidaksesuain dengan pendidikannya, hal tersebut dapat diminimalisir dengan sertifikasi tenaga kerja. Keterserapan untuk lulusan SMK Teknik Bangunan belum optimal, dari segi ketersediaan yang ada, jumlah permintaan masih minim, namun dari segi kebutuhan di lapangan mengalami kesulitan menemukan lulusan SMK Teknik Bangunan.
\end{abstract}

Kata Kunci : Supply, Demand, Tenaga Kerja, Bidang Bangunan.

\footnotetext{
${ }^{1}$ Mahasiswa Program Studi Pendidikan Teknik Bangunan FKIP UNS

${ }^{2}$ Pengajar Program Studi Pendidikan Teknik Bangunan FKIP UNS
} 


\title{
ANALYSIS OF SUPPLY AND DEMAND OF LABOR OF BUILDING IN KARANGANYAR DISTRICT \\ Fajar Avani', A G Tamrin', Taufiq Lilo Adi Sucipto ${ }^{2}$ \\ Email :jajang995@gmail.com
}

\begin{abstract}
The objectives of this study are : (1) To find out the conditions of availability labor in the building area in karanganyar regency, (2) Know the conditions of labor requirements in the building sector in Karanganyar regency, (3) Know the suitability of qualifications and competencies between tha availability and needs of the building sector in Karanganyar regency. This research is a qualitative study with a case study approach. Data collection with documents and interviews, data analysis using interactive data analysis model through 3 stages, (1) data reduction, (2) data presentation, (3) conclusions/ verification. Data was obtained from the Manpower Office and the Contractors' Association in Karanganyar. The results showed that (1) The availability of labor in the building area of Karanganyar district in 2018 from the Vocational School and the Manpower Office as many as 111 peoples, the available skills were carpentry and building drawing techniques. (2) The workforce needs of the Karanganyar district building in 2018 for one project are 106 peoples. The work competencies needed are experts, skilled workers, and brute labor. (3) Suitability between skills and building work is appropriate, but there is a mismatch with education, this can be minimized by labor certification. Absorption for Building Engineering Vocational School graduates is not optimal, in terms of availability, the number of requests is still minimal, but inn terms of needs in the field it is difficult to find graduates of Building Engineering Vocational Schools.
\end{abstract}

Keywords : Supply, Demand, Labor, Building.

\footnotetext{
${ }^{1}$ Student of Civil Engineering of Education FKIP UNS

${ }^{2}$ Lecturer of Civil Engineering of Education FKIP UNS
} 


\section{PENDAHULUAN}

Pembangunan di setiap daerah akan selalu diikuti dengan pengembangan pada infrastruktur bangunan. Karanganyar merupakan kabupaten di Jawa Tengah yang sedang mengalami pengembangan pada infrastruktur bangunan dari tahun 2013 hingga 2018, dan akan mendapat perhatian lebih dari pemerintah kabupaten Karanganyar ke depannya (Wicaksono, 2017). Tahun 2018 terdapat 106 proyek bangunan (jalan dan jembatan, gedung, irigasi dan drainase, saluran air bersih dan air minum) yang dikelola pemerintah daerah kabupaten Karanganyar (LPSE Karanganyar, 2018). Dalam pengerjaan proyek, membutuhkan tenaga kerja untuk menyelesaikannya.

Kebutuhan (demand) tenaga kerja harus diimbangi dengan ketersediaannya (supply). Salah satu ketersediaan tenaga kerja adalah melalui institusi pendidikan SMK, karena SMK dianggap memiliki kompetensi dasar dan cepat menyesuaikan dengan keadaan di lapangan. Menurut UU No 20 tahun 2003 pasal 15 tentang Sistem Pendidikan Nasional, adanya SMK dirancang untuk menyiapkan para lulusan bekerja di bidang tertentu.

Direktur Pembinaan SMK Kementerian Pendidikan Nasional, Joko Sutrisno menyatakan bahwa selain dibekali pengetahuan sesuai dengan program studi keahlian, peserta didik di SMK juga lebih banyak melakukan praktik agar pengetahuan peserta didik mengenai lapangan lebih luas. (Dwitagama, 2008).

SMK Teknik Bangunan adalah sumber ketersediaan tenaga kerja untuk industri jasa konstruksi dalam menyelesaikan proyek bangunan. Kabupaten Karanganyar memiliki beberapa SMK dengan berbagai jurusan, namun untuk jurusan Teknik Bangunan masih terlampau kecil, hanya ada satu SMK Teknik Bangunan di sekolah swasta, dengan satu kompetensi keahlian yaitu Teknik Gambar Bangunan.

Sedangkan SMK Teknik Bangunan sendiri memiliki daya tarik yang rendah, menurut Isnandar (2014, 4) bahwa stigma dan citra negatif pada SMK Teknik Bangunan jika lulus "akan menjadi tukang/kuli bangunan", padahal lulusan SMK Bangunan masih tetap dibutuhkan oleh DUDI.

Berdasarkan informasi di atas, muncul beberapa pertaanyaan, yaitu bagaimana kondisi ketersediaan dan kebutuhan tenaga kerja bidang bangunan, bagaimana kesesuaian antara ketersediaan dan kebutuhan?, Apakah secara kuantitas sudah seimbang? Apakah secara kualitas sudah sesuai kualifikasi dan kompetensi tenaga kerjanya? Apakah dengan keberadaan satu SMK Teknik Bangunan sudah mampu memenuhi kebutuhan tenaga kerja bidang bangunan secara optimal? Ataukah Karanganyar memang tidak memerlukan keberadaan SMK Teknik Bangunan?

Manfaat yang diharakan dari penelitian ini adalah dapat digunakan sebagai pedoman kepada SMK Teknik Bangunan Karanganyar dalam mempersiapkan lulusannya bekerja di industri jasa konstruksi, sebagai acuan industri jasa konstruksi dalam melakukan permintaan tenaga kerja, dan sebagai bahan pertimbangan pemerintah daerah dan pemerintah provinsi dalam menentukan optimalisasi jurusan SMK Teknik Bangunan di Karanganyar.

\section{METODE PENELITIAN}

Jenis penelitian yang digunakan pada penelitian ini adalah penelitian kualitatif, yaitu metode penelitian naturalistik, karena penelitiannya dilakukan pada kondisi yang alamiah, data yang terkumpul dan analisisnya bersifat kualitatif. Metode kualitatif digunakan untuk mendapatkan data yang mendalam, yaitu suatu data yang 
mengandung makna. (Sugiyono, 2015 : 14-15), dengan pendekatan studi kasus instrumental, studi yang menekankan pada kasus tunggal yang dimaksudkan untuk mendeskripsikan secara detail, sehingga membentuk satu konstruk. Kasus hanya dijadikan sebagai 'sarana' untuk memahami hal lain di luar kasus. (Idrus, 2007 : 79). Kegiatan penelitian dilakukan di Dinas Tenaga Kerja dan Asosiasi Kontraktor Karanganyar. Teknik pengumpulan data pada penelitian ini dengan melakukan studi dokumen dan wawancara. Analisis data menggunakan analisis menurut Miles dan Huberman, yang melalui 3 tahap, yakni reduksi data, penyajian data dan kesimpulan/ verifikasi.

\section{HASIL DAN PEMBAHASAN}

Data yang didapatkan dalam penelitian ini meliputi kondisi tenaga kerja bidang bangunan di Karanganyar tentang ketersediaan, kebutuhan dan kesesuaian kualifikasi kompetensi antara ketersediaan dan kebutuhan tenaga kerja bidang bangunan.

Tabel 1. Ketersediaan (Supply) Tenaga Kerja Berdasarkan Keterampilan/ Keahlian (Sumber : Temuan Penelitan)

\begin{tabular}{|l|l|c|}
\hline $\begin{array}{l}\text { Supply } \\
\text { Tenaga } \\
\text { Kerja }\end{array}$ & $\begin{array}{l}\text { Keterampilan/ } \\
\text { Keahlian }\end{array}$ & Jumlah \\
\hline $\begin{array}{l}\text { SMK Satya } \\
\text { Karya }\end{array}$ & $\begin{array}{l}\text { Gambar } \\
\text { bangunan }\end{array}$ & 34 \\
\hline $\begin{array}{l}\text { Supply } \\
\text { Tenaga } \\
\text { Kerja }\end{array}$ & $\begin{array}{l}\text { Keterampilan/ } \\
\text { Keahlian }\end{array}$ & Jumlah \\
\hline Disnaker & $\begin{array}{l}\text { Tukang } \\
\text { bangunan }\end{array}$ & 15 \\
\cline { 2 - 3 } & Tukang kayu & 33 \\
\cline { 2 - 3 } & $\begin{array}{l}\text { Tukang pasang } \\
\text { atap }\end{array}$ & 12 \\
\cline { 2 - 3 } & Tukang kaca & 17 \\
\hline \multicolumn{2}{|l|}{ Total } & 111 \\
\hline
\end{tabular}

Tabel 2. Ketersediaan (Supply) Tenaga Kerja Berdasarkan Asal Daerah (Sumber : Temuan Penelitian)

\begin{tabular}{|l|c|c|c|}
\hline \multirow{2}{*}{$\begin{array}{l}\text { Supply } \\
\text { Tenaga Kerja }\end{array}$} & \multicolumn{3}{|c|}{ Asal } \\
\cline { 2 - 4 } & KRA & $\begin{array}{l}\text { Luar } \\
\text { KRA }\end{array}$ & Jumlah \\
\hline $\begin{array}{l}\text { SMK Satya } \\
\text { Karya }\end{array}$ & 27 & 7 & 34 \\
\hline Disnaker & 77 & - & 77 \\
\hline Jumlah & 104 & 7 & 111 \\
\hline Prosentase & $93,7 \%$ & $6,3 \%$ & $100 \%$ \\
\hline
\end{tabular}

Tabel 3. Kebutuhan (Demand) Tenaga Kerja (Sumber : Temuan Peneliti)

\begin{tabular}{|c|c|c|c|c|}
\hline \multicolumn{5}{|c|}{$\begin{array}{c}\text { Kebutuhan Tenaga Kerja (Proyek } \\
\text { Bangunan Gedung Baperlitbang } \\
\text { Karanganyar) }\end{array}$} \\
\hline $\begin{array}{l}\text { Klasi- } \\
\text { fikasi }\end{array}$ & $\begin{array}{l}\text { Pendi } \\
- \\
\text { dikan }\end{array}$ & $\begin{array}{l}\text { Kompe } \\
\text {-tensi }\end{array}$ & $\begin{array}{l}\text { Jum } \\
\text {-lah }\end{array}$ & Asal \\
\hline $\begin{array}{l}\text { Tenaga } \\
\text { Ahli }\end{array}$ & S1 & SKA & \multirow[b]{2}{*}{6} & \multirow{3}{*}{$\begin{array}{l}\text { Kr. } \\
\text { Anya } \\
\text { r dan } \\
\text { luar } \\
\text { Kr. } \\
\text { Anya } \\
r\end{array}$} \\
\hline $\begin{array}{l}\text { Tenaga } \\
\text { Terampi } \\
1\end{array}$ & $\begin{array}{l}\text { SD- } \\
\text { SMA/ } \\
\text { SMK }\end{array}$ & SKT & & \\
\hline $\begin{array}{l}\text { Tenaga } \\
\text { Terampi } \\
1\end{array}$ & $\begin{array}{l}\text { SD- } \\
\text { SMA/ } \\
\text { SMK }\end{array}$ & $\begin{array}{l}\text { Job } \\
\text { desc }\end{array}$ & \multirow{2}{*}{100} & \\
\hline $\begin{array}{l}\text { Tenaga } \\
\text { Kasar }\end{array}$ & $\begin{array}{l}\text { SD/ } \\
\text { SMP }\end{array}$ & $\begin{array}{l}\text { Job } \\
\text { desc }\end{array}$ & & $\begin{array}{l}\text { Kr. } \\
\text { Anya } \\
\text { r }\end{array}$ \\
\hline
\end{tabular}

Berdasarkan analisis data antara hasil studi dokumen lulusan SMK Teknik Bangunan dan pencari kerja di Dinas Tenaga kerja dengan hasil wawancara kepada informan dari Dinas Tenaga Kerja dan Asosiasi Kontraktor kabupaten Karanganyar, dapat diuraikan dalam pembahasan sebagai berikut :

\section{Supply Tenaga Kerja Bidang Bangunan}

Ketersediaan tenaga kerja bidang bangunan berasal dari beberapa tingkat pendidikan formal, mulai dari SD sampai sarjana, masingmasing tingkatan pendidikan dalam tenaga kerja bangunan memiliki jenjang kualifikasi, mulai dari terampil kelas III sampai ahli utama, 
untuk lulusan SMK Teknik Bangunan yang menjadi fokus penelitian, termasuk ke dalam terampil kelas II, namun selain dari SMK, terdapat pencari kerja di Disnaker sebagai angkatan kerja.

Keterampilan angkatan kerja diantaranya gambar bangunan untuk lulusan SMK Teknik Bangunan dan beberapa keterampilan pertukangan dari Disnaker. Secara kuantitas, angkatan kerja yang tersedia ada 111 orang, 34 dari lulusan SMK Teknik Bangunan tahun 2018, 77 dari pencari kerja di Disnaker tahun 2018.

Asal tenaga kerja didominasi dari karanganyar, karena memang peneliti melakukan pengumpulan data di Karanganyar. Namun, dari data yang diperoleh tersebut masih sedikit dari sumber angkatan kerja bidang bangunan yang ada.

\section{Demand Tenaga Kerja Bidang Bangunan}

Kebutuhan tenaga kerja bidang bangunan diperoleh dari peluang kerja yang telah terisi di industri jasa konstruksi, dalam hal ini adalah proyek bangunan. Pengelompokan tenaga kerja di proyek bangunan terbagi menjadi tenaga ahli, tenaga terampil dan tenaga kasar. Kebutuhan akan tenaga kerja yang paling banyak dan sangat penting yaitu tenaga terampil kelas II, dengan syarat pendidikan minimal SMK/ SMA.

Tingkat lulusan pendidikan secara keseluruhan, mulai dari SD sampai sarjana, karena apapun pendidikannya, pasti akan mendapatkan peluang jadi tenaga kerja, yang membedakan hanyalah posisi kerja sesuai dengan kualitas keahlian atau keterampilannya.Meskipun kebutuhan akan tenaga kerja lulusan SMK banyak, tidak semua seluruhnya dari SMK Teknik Bangunan, ada beberapa tenaga terampil kelas II dari lulusan SMK Teknik Mesin, Otomotif, dll dikarenakan faktor ketersediaan lulusan SMK Teknik Bangunan yang sedikit. Namun, berdasarkan dokumen proyek yang diteukan, mereka yang pendidikannya di luar bidang bangunan, telah memiliki sertifikat terampil, sehingga wajar apabila digunakan menjadi tenaga kerja.

Sertifikat tenaga kerja adalah bukti bahwa kompetensi tenaga kerja. Bidang konstruksi ada 2 sertifikat, yaitu SKA untuk tenaga ahli dan SKT untuk tenaga terampil. Tenaga yang bersertifikat akan ditempatkan menjadi tenaga inti, seperti site manajer, pelaksana atau pembantu pelaksana, sedangkan untuk tenaga yang belum bersertifikat, kemampuannya diukur dari seberapa mampu melaksanakan pekerjaan sesuai job desc atau arahan dari atasannya.

Kuantitas atau jumlah kebutuhan tenaga kerja bangunan dalam satu pekerjaan proyek, dalam kasus ini proyek pembangunan gedung baperlitbang karanganyar, membutuhkan 5-6 tenaga inti dan 100 tenaga non inti. Daerah asal tenaga kerja tenaga ahli dan terampil tidak terbatas, karena ukuran mereka adalah kompetensinya, biasanya sudah "langganan" dengan kontraktor yang membawanya. Sedangkan tenaga kasar, prioritas dari masyarakat sekitar pembangunan proyek, sehingga tercipta lowongan kerja padat karya.

\section{Kesesuaian Kualifikasi Kompetensi Tenaga Kerja Bidang Bangunan}

Kondisi ketersediaan dan kebutuhan tenaga kerja bidang bangunan apabila dibenturkan di pasar kerja, akan terdapat beberapa kesesuaian dan ketidaksesuaian dalam 
hal jenjang kualifikasi pendidikan ataupun kompetensinya. Ada sedikit ketidaksesuaian antara pendidikan dengan pekerjaan tenaga kerja, yaitu sebagian tenaga kerja bidang bangunan bukan berasal dari lulusan bidang bangunan, Namun ketidaksesuaian tersebut mampu ditutuupi dengan sertifikat tenaga kerja yang dimiliki. Dari kondisi ini mengandung kelemahan yaitu luluusan dari SMK Teknik Bangunan kurang memiliki daya saing. Di sisi lain, kompetensi tenaga kerja yang tersedia di Dinas Tenaga Kerja sangat minimal, belum mampu untuk memnuhi kebutuhan industri jasa konstruksi.

Ketidaksesuaian kompetensi yang tersedia tersebut mempengaruhi keterserapan tenaga kerja. Karena tenaga kerja yang ditawarkan belum sesuai dengan kebutuhan industri jasa konstruksi secara kualitas, walaupun secara kuantitas sebenarnya bisa mencukupi. Selain itu, kontraktor mengalami kesulitan dalam mempekerjakan lulusan SMK Teknik Bangunan, karena minimnya ketersediaan. Menurutnya, bidang bangunan masih sepi peminat dari kalangan pelajar, sehingga mempengaruhi output dari lulusan SMK Teknik Bangunan untuk dijadikan tenaga kerja.

\section{SIMPULAN}

Berdasarkan data hasil penelitian dan pembahasan yang telah dijelaskan pada bab sebelumnya dapat ditarik kesimpulan sebagai berikut :

1. Kondisi ketersediaan angkatan kerja bidang bangunan sudahh tersedia, yaitu berasal dari SMK Teknik Bangunan dan pencari kerja bidang bangunan di Disnaker sebanyak 111 orang, namun masih belum bisa mencukupi dari segi kualitas atau kompetensinya. Kualitas angkatan kerja yang ditawarkan masih rendah, sehingga keterserapannya di industri jasa konstruksi ikut rendah.

2. Kondisi kebutuhan tenaga kerja bidang bangunan untuk satu pekerjaan proyek membutuhkan 106 tenaga kerja, baik ahli, terampil maupun tenaga kasar. Kebutuhan akan tenaga kerja terampil lulusan SMK Teknik Bangunan cukup tinggi, namun kendalanya adalah ketersediaannya yang minim, sehingga kontraktor sedikit kesulitan untuk memberdayakan lulusan SMK Teknik Bangunan secara optimal.

3. Kualifikasi pendidikan dengan bidang pekerjaan bangunan masih ada ketidaksesuaian, namun secara skill atau kompetensi tenaga kerja sudah ada keterkaitan dengan kebutuhan industri jasa konstruksi, karena adanya sertifikat tenaga kerja yang dimiliki.

\section{SARAN}

1. SMK Teknik Bangunan

Karanganyar, agar menjalin hubungan baik dengan mitra kerja di industri jasa konstruksi, akan lebih baik lagi memperluas kemitraan, sebagai bekal siswa untuk bekerja setelah lulus.

2. Dinas Tenaga Kerja, agar melakukan pelatihan tenaga kerja bidang bangunan. Untuk meningkatkan kualitas ketersediaan tenaga kerja.

3. Dinas Pendidikan SMK provinsi Jawa Tengah, agar melakukan monitoring kembali terkait optimalisasi jurusan Teknik Bangunan di Karanganyar.

4. Mahasiswa PTB UNS, agar mempersiapkan diri menjadi pendidik 
bidang bangunan yang baik, yang mampu memahamkan siswanya bahwa Teknik Bangunan memiliki potensi peluang kerja yang baik.

\section{DAFTAR PUSTAKA}

Aspekindo. (2018). Dokumen Pelelangan Proyek. Karanganyar : Sari Makmur.

Aspekindo. (2018). Dokumen Pelelangan Proyek. Karanganyar : Pilar Abadi.

Aspeknas. (2018). Dokumen Pelelangan Proyek. Karanganyar : Bettindo Bintang Perkasa.

Dinas Komunikasi Informasi Kabupaten Karanganyar. (2018). Pembangunan Infrastruktur Jalan Menjadi Prioritas Utama. Karanganyar : Dinas Komunikasi Informasi Kabupaten Karanganyar.

Dinas Tenaga Kerja Kabupaten Karanganyar. (2018). Pencari Kerja. Karanganyar : Dinas Tenaga Kerja Kabupaten Karanganyar.

Dwitagama, D. (2008). Siswa SMK Dipersiapkan untuk Siap Kerja Setelah Lulus Sekolah. diakses pada 19 Mei 2018 pukul 19.45 dari https://dedidwitagama.wordpress.co m/2008/02/08/mau-kerja-masuksmk-ajal

Idrus, M. (2007). Metode Penelitian Ilmu-Ilmu Sosial (Pendekatan Kualitatif dan Kuantitatif). Yogyakarta : UII Press.

Isnandar. (2014). Manajemen Penyelenggaraan Revitalisasi Kurikulum, Intensitas Kerjasama, dan Kualitas Pembelajaran dalam
Upaya Pencitraan SMK Program Keahlian Teknik Bangunan di Jawa Timur. Disertasi tidak diterbitkan. Malang : Pascasarjana Universitas Negeri Malang.

LPSE Karanganyar. (2018). Paket Pekerjaan Konstruksi. Karanganyar : Dinas Pekerjaan Umum dan Perumahan Rakyat Kabupaten Karanganyar.

Pedoman Penulisan Skripsi Fakultas Keguruan Dan Ilmu Pendidikan Universitas Sebelas Maret Tahun 2016. (2016). Surakarta : UNS Press.

Peraturan Menteri Pekerjaan Umum No 9 Tahun 2013 tentang Persyaratan Kompetensi untuk Subkualifikasi Tenaga Ahli dan Tenaga Terampil Bidang Jasa Konstruksi. Kementerian Pekerjaan Umum.

Sugiyono. (2015). Metode Penelitian Pendidikan. Bandung : Alfabeta.

Undang-Undang Republik Indonesia No. 13 Tahun 2003 Tentang Ketenagakerjaan. (2006). Jakarta : Pustaka Pelajar.

Undang-Undang Republik Indonesia No. 20 Tahun 2003 Tentang Sistem Pendidikan Nasional. (2003). Jakarta : Depdiknas.

Wicaksono, B. ( 2017, 13 September). Pemkab Karanganyar Kebut Pembangunan Infrastruktur Jalan. RADAR SOLO. Diperoleh 20 April 2018, dari https://www.jawapos.com/radarsolo Iread/2017/09/13/13384/pemkabkaranganyar-kebut-pembangunaninfrastruktur-jalan 